\title{
Interaction between Soil Moisture and Air Temperature in the Mississippi River Basin
}

\author{
Chunling Tang ${ }^{*}$, Dong Chen ${ }^{2}$ \\ ${ }^{1}$ Comutational Exposure Division, Environmental Protection Agency, Research Triangle Park, Durham, NC, USA \\ ${ }^{2}$ Key Laboratory of Water Cycle and Related Land Surface Processes, Institute of Geographic Sciences and Natural Resources \\ Research, Chinese Academy of Sciences, Beijing, China \\ Email: *tang.chunling@epa.gov
}

How to cite this paper: Tang, C.L. and Chen, D. (2017) Interaction between Soil Moisture and Air Temperature in the Mississippi River Basin. Journal of Water Resource and Protection, 9, 1119-1131. https://doi.org/10.4236/jwarp.2017.910073

Received: July 28, 2017

Accepted: September 12, 2017

Published: September 15, 2017

Copyright $\odot 2017$ by authors and Scientific Research Publishing Inc. This work is licensed under the Creative Commons Attribution International License (CC BY 4.0).

http://creativecommons.org/licenses/by/4.0/ (c) (i) Open Access

\begin{abstract}
Increasing air temperatures are expected to continue in the future. The relation between soil moisture and near surface air temperature is significant for climate change and climate extremes. Evaluation of the relations between soil moisture and temperature was performed by developing a quantile regression model, a wavelet coherency model, and a Mann-Kendall correlation model from 1950 to 2010 in the Mississippi River Basin. The results indicate that first, anomaly air temperature is negatively correlated to anomaly soil moisture in the upper and lower basin, and however, the correlation between them are mixed in the middle basin. The correlation is stronger at the higher quantile $\left(90^{\text {th }}\right)$ of the two variables. Second, anomaly soil moisture and air temperature show strong coherency in annual frequency, indicating that the two variables are interannually correlated. Third, annual air temperature is significant negatively related to soil moisture, indicating that dry (wet) soil leads to warm (cool) weather in the basin. These results have potential application to future climate change research and water resource management. Also, the strong relationship between soil moisture and air temperature at annual scale could result in improved temperature predictability.
\end{abstract}

\section{Keywords}

Soil Moisture, Air Temperature, Quantile Regression Model, Wavelet Transform Coherency, Climate Change

\section{Introduction}

Increase in temperature has been observed as a consequence of climate change over the last century. Air temperature (T) is anticipated to continue increasing 
in the future, while the mechanisms for the increase remain uncertain [1] [2]. Soil moisture (SM) has been shown to have influence on $\mathrm{T}$ by controlling the partitioning between sensible and latent heat, and interaction between SM and T accounts for about two-thirds of the climate change signal in the future climate models [2]. A better understanding of the relationship between them might provide sharper insight into these mechanisms [3] [4] [5] [6]. With this concept in mind, in this study, we investigated the relation between SM and T and the results are essential for understanding the global temperature rises specifically and global warming more generally.

Several studies have pointed to the relation between SM and T to help explain projected global warming [3] [5] [7]-[12] and extreme climate events (e.g. drought and flood). Many studies show that interaction between SM and T plays a significant role in extreme climate condition by land atmosphere interactions [6] [8] [13] [14]. Two sets of apparently contradictory results have been presented, namely that a reduction in SM leads to an increased T [3] [9] [10] [11] [12] [15] [16], and while other studies indicate that a SM deficit leads to cold weather [3] [12] [16] [17] [18]. For example, positive feedbacks exist over some of Northeast Asia, even at a less significant level [3] [18] [19]. However, significant negative feedbacks between $\mathrm{SM}$ and $\mathrm{T}$ exist at wet transition zones in Northern China. SM deficit induces higher air $\mathrm{T}$ in the plains, well reduces the $\mathrm{T}$ over mountains in France from 1989 to 2008 in [20].

However, due to a lack of sufficient long-term and high-resolution SM data, systematically synthesizing the relationship between SM and T remains a significant challenge. Here we propose the first exclusive analysis between SM and T, to study the relations by a number of factors, including Quantile Regression Model (QRM), Wavelet Transform Coherency (WTC) analysis, and Mann-Kendall trends in the Mississippi River Basin (MRB). Many studies [10] [17] [21] showed that SM is a drought indicator, so, the interaction between SM and T helps both understanding the climate change and the climate extremes. The MRB, as the largest basin of the United States, spans a wide range of climatic regions with snow-dominated, transitional, and rain-dominated regions, the results of the research might provide an indication of the relation between SM and T for the whole nation.

\section{Study Area and Model}

\subsection{Study Area}

The study area is the MRB, which drains 41 percent (41\%) of the water from all or part of the 31 states in the United States, and are home to over 100 globally important aquatic species such as walleye, sauger and perch. Furthermore, as the largest basin in nation, the MRB spans a wide range of climatic regions with snow-dominated, transitional, and rain-dominated regions. Climate changes have occurred and are anticipated to continue in the future. Many changes indicate this region is also undergoing a system wide response to climate change. 
Given the importance of the MRB in terms of environmental processes, nature resources, and economics, this study provided significant meanings for the MRB.

\subsection{Variable Infiltration Capacity (VIC) Model}

In MRB, long-term observation SM data cannot be obtained, therefore, the VIC [22] model was utilized to simulate SM for a daily time step at $1 / 8^{\circ}$ spatial (about $12 \mathrm{~km}$ ) resolution for the period of 1950 to 2010 . The methods used to calibration of the simulation results are reported in more detail in [10] [23].

The VIC model is a macroscale, grid-based water and energy balance model, which has been successfully applied to many large river basins with good results [22]-[28]. Distinguishing features of the VIC model include the sub-grid variability in SM, land surface vegetation, precipitation, and topography in use of the elevation bands.

In this study, the VIC model is forced with parameter files and meteorological forcing. The parameter files include soil parameters, vegetation parameters, and elevation bands. The soil parameter files describe the unique soil properties for each grid cell, the main parameters include soil texture information, soil bulk densities, hydraulic conductivities, and thickness of each soil layer, infiltration capacities, and base flow parameters. The VIC model uses a complex and explicit conceptual framework in accounting for variations in SM. The soil was divided to three layers with depth of each layer specified for each grid cell as derived during model calibration in this study. The thin upper layer $(\sim 10 \mathrm{~cm})$ simulates runoff processes in near surface soil layers, and thicker second layer $(50 \sim 80$ $\mathrm{cm})$ and third layer $(100 \mathrm{~cm} \sim 250 \mathrm{~cm})$ represent slower storage and drainage processes in this study. Deep layer SM has a longer memory than many other land surface variables (such as precipitation and temperature) because SM reservoir is a larger storage term (than evapotranspiration and snowpack) in the water balance [21]. SM of the third layer was used in details for the analysis because of its consistency and longer memory in the study. The daily simulated SM are aggregated to month SM then converted to anomalies by subtracting the mean monthly SM for each model grid cell from 1950 to 2010.

The vegetation parameters describe different land cover characterization, which has a total of 14 different land cover classes. The primary characteristic of the land cover that affects the model simulation is Leaf Area Index (LAI). The elevation band files define the properties of each elevation band to improve the performance of the model in changing topography, especially mountainous regions (upper MRB). Four elevation bands were used in this study.

The meteorological data include observed precipitation, maximum temperature, minimum temperature, and wind. Daily precipitation and temperature were obtained by interpolating daily observation data from National Weather Service Cooperative Observe with scaling for topographic effects using the Parameter-elevation Regressions on Independent Slope Model (PRISM) precipita- 
tion map [23]. Daily wind speed was obtained from National Centers for Environmental Prediction (NCEP) [23].

\subsection{Model Calibration}

The VIC model was calibrated at six United States Geological Survey (USGS) gaging stations for which stream flow observations were available from 1950 to 2010.

The VIC model calibration includes calibrating six parameters: a) the infiltration parameter which controls the partitioning of rainfall (or snowmelt) into infiltration and direct runoff; b) the second and third soil layer thicknesses, which affect the water available for transpiration and baseflow respectively; c) $D s_{\max }$, $D s$, and $W s$, which are baseflow parameters and also are estimated. $D s_{\max }$ is the maximum baseflow velocity, $D s$ is the fraction of maximum baseflow velocity, and $W s$ is the fraction of maximum soil moisture content of the third soil layer at which non-linear baseflow occurs. These three baseflow parameters determine how quickly the water stored in the third soil layer is evacuated as baseflow [22].

A 30-year period (1950-1979) of the 60-year record was utilized for the calibration process. This 30 -year period encompassed a range of extreme climate conditions (e.g., flood and drought), and normal years for testing the two models' performance. A separate 30-year period (1980-2009) was used for model validation. That period also encompassed a range of climatic conditions under which we evaluated the models' performance. Two standard statistical techniques, the root meansquare error (RMSE) and the widely used coefficient of determination $\left(R^{2}\right)$ value, were used to test and evaluate the accuracy of the model simulations.

\section{Methods}

\subsection{Quantile Regression Model (QRM)}

QRM is a statistical technique intended to estimate, and conduct inference about conditional quantile functions. QRM is capable of providing a more complete statistical analysis of the stochastic relationships among random variables, which may best represent the true relationship between SM and air T.

The QRM can be expressed as:

$$
y_{i}=\beta_{0}^{(p)}+\beta_{1}^{(p)} x_{i}+\varepsilon_{i}^{(p)}
$$

where, $0<p<1$ indicates the proportion of the population having scores below the quantile at $p$. where: $x_{i}$ and $y_{i}$ are pairs of the data, for based on the sample of the SM and air T. $\varepsilon_{i}^{(p)}$ is the error term, which is independent and identically distributed for $i=1,2, \cdots, n . \quad \beta_{0}^{(p)}$ is the quantile-specific parameter.

QRM estimates multiple rates of change from the minimum to maximum and therefore can provide a more complete picture of the relationship between SM and air T. Previous studies have shown that SM is most strongly related to maximum temperature [5] [7]. In this study, the $5^{\text {th }}, 10^{\text {th }}, 25^{\text {th }}, 50^{\text {th }}, 75^{\text {th }}, 90^{\text {th }}$ and 
$95^{\text {th }}$ quantiles with the $50^{\text {th }}$ quantile representing the median response and $5^{\text {th }}$ and $95^{\text {th }}$ representing the extreme climate conditions were used.

\subsection{Wavelet Transform Coherency (WTC)}

To furtherer understand the correlation between SM and air T; the WTC [29] [30] [31] was utilized. The continues wavelet transforms a one-dimensional time series to a two-dimensional time-frequency image simultaneously which shows both the amplitude of any periodic signals within the series and how this amplitude varies with time. The continuous wavelets transform $W_{n}$ of a discrete sequence of observations $X_{n}$ is described as following:

$$
W_{n}^{\chi}(s)=\sum_{n^{\prime}}^{N-1} x_{n^{\prime}} \psi *\left[\frac{\left(n^{\prime}-n\right) \delta t}{s}\right]
$$

where $n$ is the localized time index, $s$ is the wavelet scale, $\delta t$ is the sampling period, $N$ is the number of points in the time series, and the asterisk indicates the complex conjugate.

The wavelet coherency was used to identify frequency bands and time intervals where two times series were related [29]. The wavelet coherency $R_{n}$ is defined as:

$$
R_{n}^{2}(s)=\frac{\left|\left\langle s^{-1} W_{n}^{X Y}(s)\right\rangle\right|^{2}}{\left\langle s^{-1}\left|W_{n}^{X}(s)\right|^{2}\right\rangle\left\langle s^{-1}\left|W_{n}^{Y}(s)\right|^{2}\right\rangle}
$$

where, \langle\rangle indicates smoothing in both time (using Gaussian function) and scale (using Boxcar filter). The statistical significance level of the wavelet coherence is estimated using Monte Carlo methods [29].

\subsection{Mann-Kendall Test}

Trends in annual time series of SM and T were estimated and tested at the 5\% significance level using the non-parametric Mann-Kendall test applied to MRB from 1950 to 2010, which is robust and distribution independent. It is a nonparametric trend test that has been widely used in studies dealing with hydro-climatic analysis [1] [32]. For the trends of the SM and air T, the null and alternative hypothesis was used, with the no trend in the null and a significant trend in the alternative hypothesis. We not only estimated the trends for SM and $\mathrm{T}$, but also intensively quantified the Man-Kendall cross relation value between SM and $\mathrm{T}$ on a grid by grid basis for over 18,000 grids in the MRB.

\section{Results}

\subsection{QRM Results}

Figure 1 shows QRM scatter plots of monthly SM anomalies and monthly air T anomalies for the lower, middle, and upper MRB. Some interesting evidences which cannot be detected by mean regression are observed. The slopes of the regression lines are negative (drier soil results in higher $\mathrm{T}$ ) for all the months and 

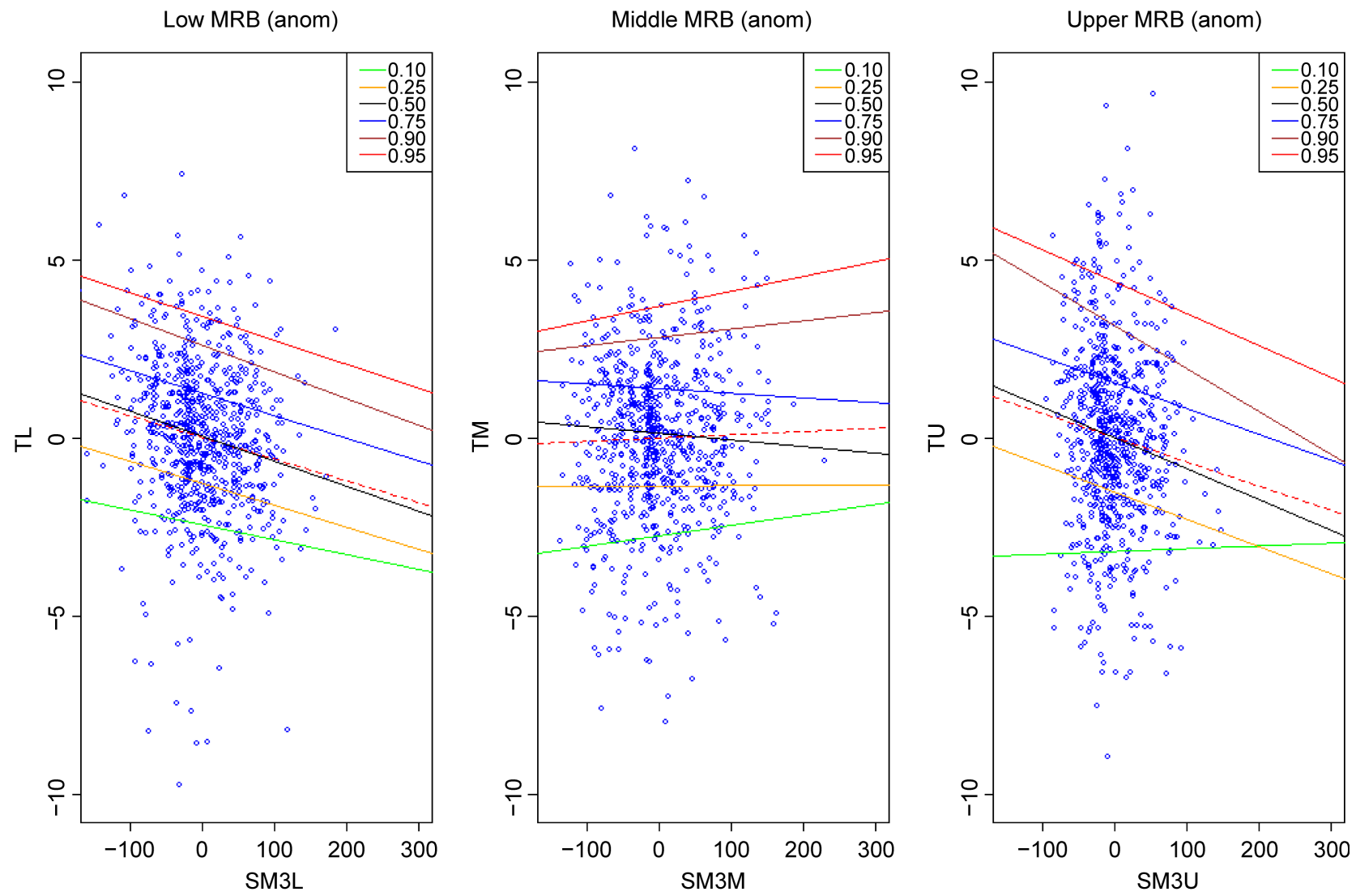

Figure 1. Relationships between monthly anomaly soil moisture and anomaly air temperature for the lower, middle, and upper MRB. The X-Axis represents the anomaly soil moisture (the 3rd layer) in the lower (SM3L), middle (SM3M), and upper (SM3U); the $\mathrm{Y}$-Axis represents the anomaly air $\mathrm{T}$ in the lower (TL), middle (TM), and upper (TU). Solid lines denote regression for selected quantiles; dashed lines represent the means.

relationships are statistically significant in lower MRB. The slopes of the regression lines get steeper as the quantile increase from $10^{\text {th }}$ quantile till $90^{\text {th }}$ quantile, and the strongest negative slopes are associated with the $90^{\text {th }}$ quantile slope which is nearly twice those of $50^{\text {th }}$ quantile. The result is similar to the relation between SM and maximum air $\mathrm{T}$ in [7]. However, the most interesting result is that the slope of $90^{\text {th }}$ is slightly steeper than $95^{\text {th }}$, which indicates that increases in $\mathrm{SM}$ lead to greater declines in air $\mathrm{T}$ along the $90^{\text {th }}$ quantile than on the $95^{\text {th }}$ quantile (extreme hot weather). During extreme climate condition, increased air $\mathrm{T}$ with more evapotranspiration (ET), more moisture in atmosphere and then more precipitation, and SM does not typically contribute greatly to air T on average in $95^{\text {th }}$ quantile. Furthermore, the higher air T results in higher ET, which lowers the wetness of soil as well. The slopes for $50^{\text {th }}$ and $75^{\text {th }}$ quantiles are almost parallel, suggesting that air $\mathrm{T}$ in these quantiles did not vary dramatically with SM.

The most interesting QRM results happened in the middle MRB, the slopes of the regression lines are mixed with positive slopes (drier soil results in lower $\mathrm{T}$ ) for lower quantiles $\left(10^{\text {th }}\right.$ and $25^{\text {th }}$ quantiles) and higher quantiles $\left(90^{\text {th }}\right.$ and $95^{\text {th }}$ quantiles), and negative slopes (drier soil results in higher $\mathrm{T}$ ) for middle quan- 
tiles ( $50^{\text {th }}$ and $75^{\text {th }}$ quantiles). The overall relations are more difficult to interpret because different areas of the domain experience different seasonal mixed precipitation (snow-domain transition to rain-domain) in different time periods. Slopes of $10^{\text {th }}$ and $95^{\text {th }}$ quantiles are somewhat steeper than for the $25^{\text {th }}$ and $90^{\text {th }}$ quantiles, respectively. These results are comparable to those shown in studies of [33] and are broadly consistent in their results on SM is most strongly associated with the high end of the temperature distribution. Slopes are positive in the areas of the domain with higher and lower temperatures. Slopes are negative for $50^{\text {th }}$ and $75^{\text {th }}$ quantile and broadly similar.

The upper MRB is strongly winter dominant, particularly at higher elevations. The winter temperature regimes largely determine how much of the winter $\mathrm{P}$ is typically stored as snow, and also play a strong role in determining the $\mathrm{T}$ sensitivity. The slope of $90^{\text {th }}$ quantile is steeper than that of $95^{\text {th }}$ quantile as that in the lower MRB. The highest slope happens in $90^{\text {th }}$ quantiles not $95^{\text {th }}$, which highlights the relation between SM and air T is weaker during extreme climate $\left(95^{\text {th }}\right.$ quantile). The slopes of the QRM quantiles are negative (drier soils result in higher $\mathrm{T}$ ) for all the quantiles except for the $10^{\text {th }}$ quantile, which might due to the frozen soil during lower $\mathrm{T}$ in the upper MRB. These impressions are strengthened by considering a sequence of density plots based on the QRM estimates.

\subsection{WTC Results}

The relationship between SM and T are further examined by decomposing the time series of SM and T in time-frequency space in order to determine both the dominant modes of variability and how those modes vary in time (Figure 2) by computing the WTC. WTC was also used to identify the phase difference (lag time) between variables of SM and T during periods of significant coherence by plotting arrows. Arrows point right for time series in-phase and left for out-of-phase. Vertical arrows pointing up when SM leads T and down when $\mathrm{T}$ leads SM.

The WTC between SM and T in the upper, middle, and lower MRB were plotted in Figure 2. The contours represent statistically significant periods (95\% significant), based on the Monte Carlo experiment. The most notable features are that SM and T are very well correlated at statistically significant level, with high coefficients in 1-yr period over the entire study period (1950-2010) for the middle and lower MRB, which means the two variables are strongly correlated on an interannual time scale. Consequently, regression techniques based on previous year's SM and T can be used to predict the coming year $\mathrm{T}$ with considerable skill. The significant regions in 1-yr band are so extensive that it is very unlikely simply by chance. Arrows all point to left indicate a very distinct anti-phase relationship for a given wavelength between SM and T (e.g., drier soil is associated with higher air $\mathrm{T}$ ). The average wavelet coherency between SM and $\mathrm{T}$ is greater than 0.85 and 0.9 for the $1-y r$ period for the middle and lower MRB, respectively. There is higher coherency in the $2-4 \mathrm{yr}$ band in the middle MRB, 


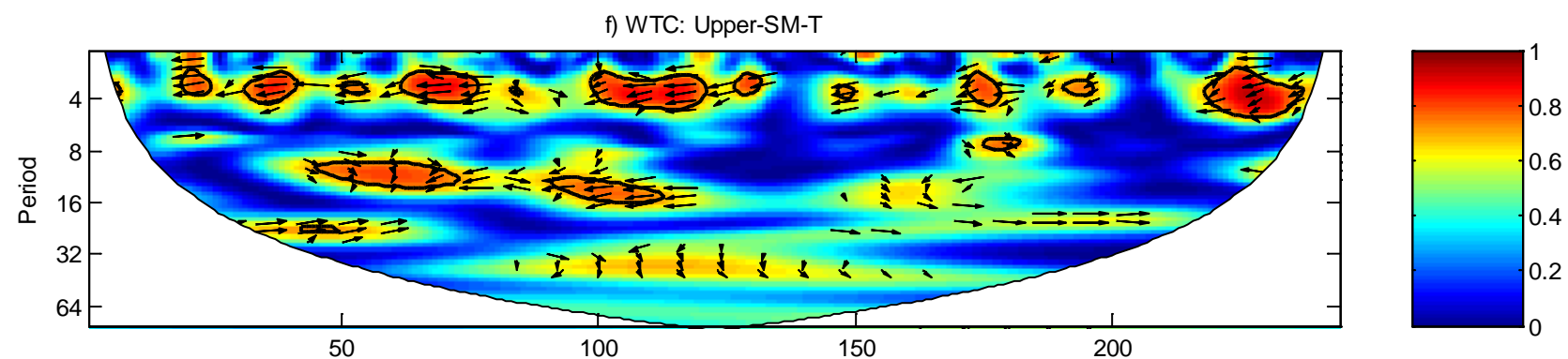

b) WTC: Middle-SM-T

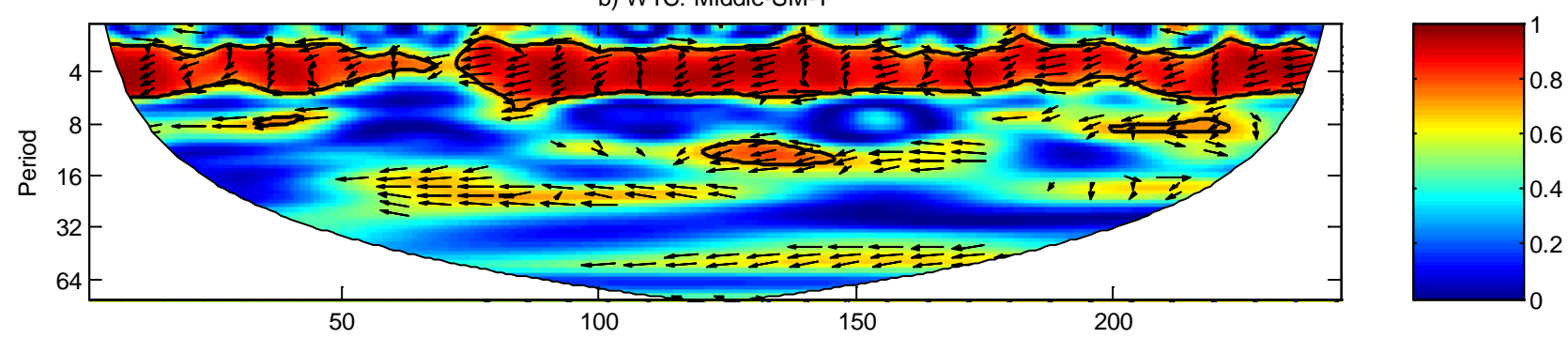

a) WTC: Lower-SM-T

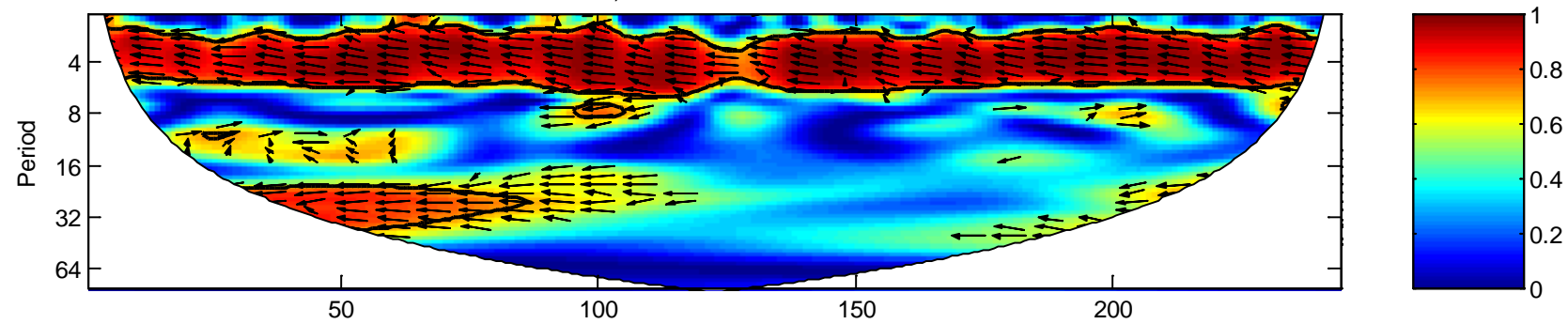

Figure 2. Wavelet coherence between the SM and T in the upper, middle, and lower MRB. The scales of the $\mathrm{x}$-axis are seasons, and $y$-axis are months. The $95 \%$ significance level is shown as a thick contour. The thin solid line indicates the cone of influence. The relative phase relationship is shown as arrows (with in-phase pointing right, anti-phase pointing left). All significant sections show anti-phase behavior.

which $\mathrm{h}$ is similar to the frequency of the El Niño Southern Oscillation (ENSO) (every $3-7 \mathrm{yr}$ ). The next best correlation band stands out being significant between $\mathrm{SM}$ and $\mathrm{T}$ is the $7-10 \mathrm{yr}$ in the lower MRB, which indicates that the SM is strongly correlated to $\mathrm{T}$ at the similar frequency patterns as the Atlantic Multi-Decadal Oscillation (AMO) (every 7 - $15 \mathrm{yr}$ ). In addition to local climate impacts, large scale climate patterns/oceanic patterns also impact the land-surface interaction in MRB. Further investigation of the relationships between AMO, ENSO, and SM and $\mathrm{T}$ could be used in developing experimental air $\mathrm{T}$ forecasting applications.

Similar as the WTC for the middle and lower MRB, the WTC in the upper MRB also shows higher coherence in 1-yr band with rather lower coherency outside of this period throughout the study period in upper MRB. However, the coherency (averaged at 0.70 ) between SM and T in upper MRB in the 1-yr period is not as significant as it in the middle and lower MRB. These differences have to do with the air $\mathrm{T}$ that determine the precipitation regimes. The upper MRB is colder, the precipitation falls as snow and snow accumulation is the do- 
minate driver of the overall SM. The sensitivity of air T to SM becomes relatively small and largely associated with snow water equivalent (SWE). The phase behavior out of 1-yr band for the SM and T does not show a strong coherency.

\subsection{Mann-Kendall Test Results}

For each $1 / 8^{\text {th }}$ degree grid cell, we quantified trends in monthly series of SM and $\mathrm{T}$ (not shown here) and tested at the 5\% significance level using the non-parametric Mann-Kendall test applied to MRB from 1950 to 2010. The T trends, although shown to be generally positive (warmer) cross the entire MRB, are larger in the upper than in the middle and lower MRB. These trends are comparable to those shown in study of [4]. These $\mathrm{T}$ trends seem to be more strongly controlled by precipitation regimes at the regional scale. Contrary to the trends in $\mathrm{T}$, the trends of SM are more mixed and difficult to analyze over the study period because SM has longer memory and not only controlled by short term climate variability in regions, but also by long-term processes like global warming and oceanic patterns. The trends of SM toward positive (wet) in upper and negative (dry) in lower domain, with no significant trends in part of middle MRB.

Using the Mann-Kendall test, we quantified the correlation between SM and T at annual scale for each grid (18,000 grids) over the study period and shown the results in Figure 3. Negative results between SM and T were pervasive the entire $\mathrm{MRB}$, in simple terms, increasing in $\mathrm{T}$ (warmer condition) is associated with decreasing SM (drier condition). The negative relations have a larger expanse and magnitude in the lower MRB, this makes sense, because this part of domain get relatively less impacts of snowmelt on SM.

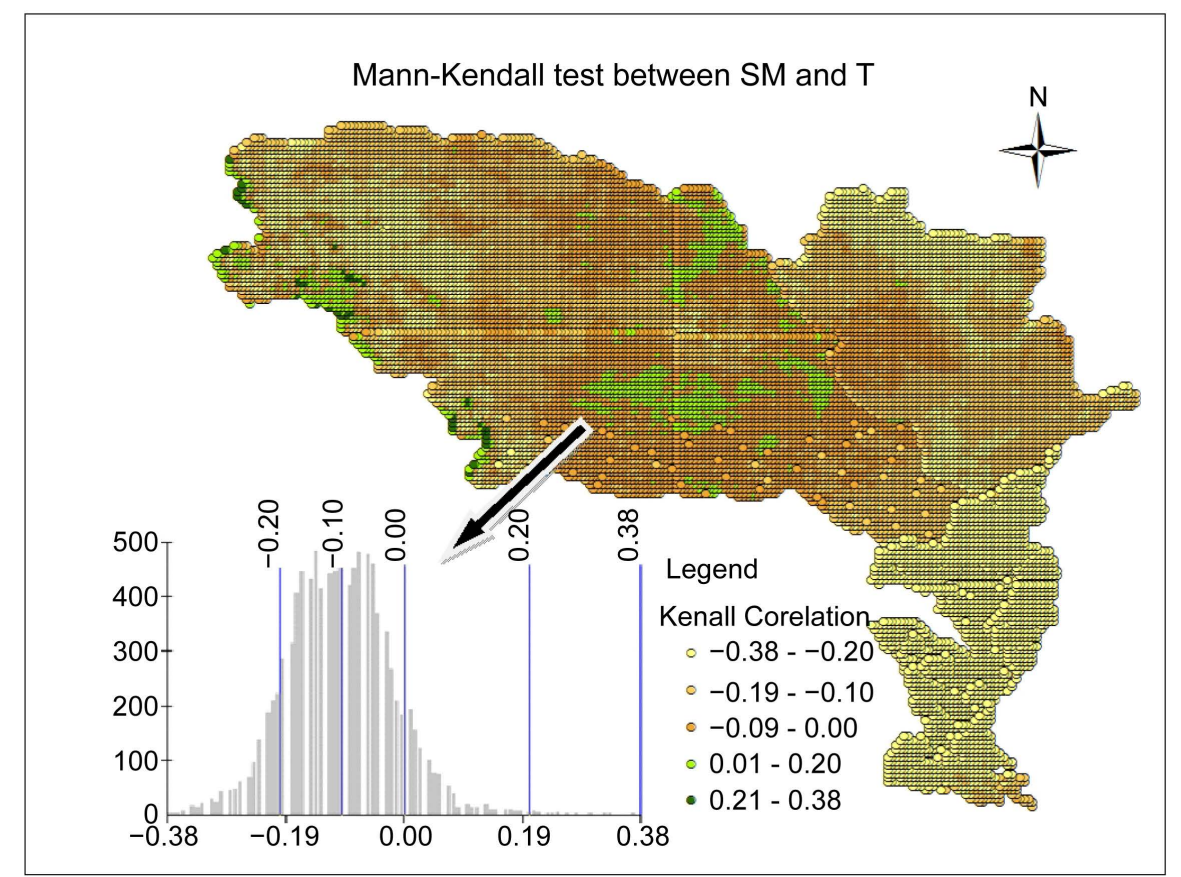

Figure 3. Mann-Kendall correlation coefficients between SM and T in the upper, middle, and lower MRB. 
The highest negative relation is found at -0.38 in lower MRB, which is due to the warmer weather in lower domain compared to the upper area because SM has a strong impact on higher air $\mathrm{T}$ than lower air $\mathrm{T}$ [34]. The values of the negative relation mainly are relatively small in absolute value over much of the domain (in comparison with negative values), well they are generally negatively consistent, which is consistence with the results in QRM section. The grids with positive correlations are spotted in the upper and mainly in the middle MRB with statistically insignificant, which is also agreed with the results in QRM section (Section 4.1). SM only positively related to $\mathrm{T}$ in small region (7\% of the $\mathrm{MRB})$ of the study area.

\section{Conclusions and Discussion}

To our knowledge, no similar analysis was performed in the MRB, it is possible the first explicit investigation of the correlation between SM and T over an extended period (1950 to 2010) in the MRB. The results have significant implications for future water availability and temperature predictability. The major findings are:

1) QRM results show that SM negatively correlated to air T for the low and upper MRB, with the higher correlation at $90^{\text {th }}$ quantile. QRM slopes are mixed (negative and positive) for the middle MRB, because the middle MRB is the transient area with snow dominant to rain dominant.

2) The T and SM are strongly correlated in 1-yr period over the entire study period, indicating that the two variables are interannually correlated. The WTC correlations between SM and T in the $2-4 \mathrm{yr}, 3-7 \mathrm{yr}$, and $7-10 \mathrm{yr}$ bands are associated with ENSO and AMO, respectively.

3) The annual $\mathrm{T}$ and SM are significantly negatively related in the MRB from 1950 to 2010, indicating that the dry (wet) soil leads to warm (cool) weather in the MRB.

The QRM results indicated that the T is strongly correlate with SM in the study area, especially the high end of SM at $90^{\text {th }}$ quantile, however, the correlation decrease at the extreme climate condition (above $95^{\text {th }}$ quantile). The relationships between SM and T are also impacted by the regional climate which makes quartile slopes mixed in the climate transition zone, e.g., the middle of MRB.

To clearly demonstrate the relationship between SM and T, we muted the impacts of other variables (such as ET and P) by calculating the WTC between them. WTC between SM and T yielded values as high as $0.70,0.85$, and 0.9 in 1-yr band in upper, middle, and lower MRB, respectively, which indicate that a correlation between SM and T exists independent of other climate and hydrologic variability in the 1-yr band. In general, the WTC results are less convincing over the upper MRB than they are over the middle and lower MRB. Reasons for this may be due to impacts of snow on SM in the upper MRB.

We mapped grid cells with statistically significant Mann-Kendall relations 
between SM and T at annual scale in the MRB. It is likely the first time to quantify the value of the trends relation between SM and T in the MRB. One can infer from the map that the negative relation is the much more promising result. $\mathrm{T}$ is mostly negatively associated with SM. The T trends have been increased (warmer) over much of the domain during the study period.

The most likely and obvious application from the results is that the results provide insight for the land and atmosphere models fully coupling for climate change. Secondly, SM can sever as a potential predictor for $\mathrm{T}$ with a long land memory and strong land-atmosphere coupling, which is important for the future climate changes, especially global warming. Thirdly, the results help understanding the extreme climate because of SM's drought index function.

Following this research, we have started land-atmosphere model coupling based on the relation between SM and T for historic, current, and climate change conditions.

\section{Acknowledgements}

This publication was supported by 1) Environmental Protection Agency (EPA) for the research program of Air, Climate, and Energy (ACE). This publication is the product of project of MDST-3 of EPA; 2) The National Science Foundation of China (51279192), the "Hundred Talents Program" of the Chinese Academy of Science. This manuscript has been subjected to U.S. EPA review and approved for publication. The views expressed in this article are those of the authors and do not necessarily represent the views or policies of the U.S. Environmental Protection Agency.

\section{References}

[1] Lettenmaier, D.P., Wood, E.F. and Wallis, J.R. (1994) Hydro-Climatological Trends in the Continental United-States, 1948-88. Journal of Climate, 7, 586-607.

[2] Seneviratne, S.I., Luthi, D., Litschi, M. and Schar, C. (2006) Land-Atmosphere Coupling and Climate Change in Europe. Nature, 443, 205-209. https://doi.org/10.1038/nature05095

[3] Feng, H. and Liu, Y. (2015) Combined Effects of Precipitation and Air Temperature on Soil Moisture in Different Land Covers in a Humid Basin. Journal of Hydrology, 531, 1129-1140. https://doi.org/10.1016/j.jhydrol.2015.11.016

[4] Hamlet, A.F., Mote, P.W., Clark, M.P. and Lettenmaier, D.P. (2007) Twentieth-Century Trends in Runoff, Evapotranspiration, and Soil Moisture in the Western United States. Journal of Climate, 20, 1468-1486. https://doi.org/10.1175/JCLI4051.1

[5] Hirschi, M., Seneviratne, S.I., Alexandrov, V., Boberg, F., Boroneant, C., Christensen, O.B., Formayer, H., Orlowsky, B. and Stepanek, P. (2011) Observational Evidence for Soil-Moisture Impact on Hot Extremes in Southeastern Europe. Nature Geoscience, 4, 17-21. https://doi.org/10.1038/ngeo1032

[6] Hursh, A., Ballantyne, A., Cooper, L., Maneta, M., Kimball, J. and Watts, J. (2017) The Sensitivity of Soil Respiration to Soil Temperature, Moisture, and Carbon Supply at the Global Scale. Global Change Biology, 23, 2090-2103.

https://doi.org/10.1111/gcb.13489 
[7] Huang, J., van den Dool, H.M. and Georgakakos, K.P. (1996) Analysis of Model-Calculated Soil Moisture over the United States (1931-1993) and Applications to Long-Range Temperature Forecasts. Journal of Climate, 9, 1350-1362.

[8] Jaeger, E.B. and Seneviratne, S.I. (2011) Impact of Soil Moisture-Atmosphere Coupling on European Climate Extremes and Trends in a Regional Climate Model. Climate Dynamics, 36, 1919-1939. https://doi.org/10.1007/s00382-010-0780-8

[9] Shinoda, M. and Yamaguchi, Y. (2003) Influence of soil moisture anomaly on temperature in the Sahel: A comparison between wet and dry decades. Journal of $\mathrm{Hy}$ drometeorology, 4, 437-447.

[10] Tang, C. and Piechota, T.C. (2009) Spatial and Temporal Soil Moisture and Drought Variability in the Upper Colorado River Basin. Journal of Hydrology, 379, 122-135. https://doi.org/10.1016/j.Journal of Hydrologyrol.2009.09.052

[11] Van den Hurk, B., Doblas-Reyes, F., Balsamo, G., Koster, R.D., Seneviratne, S.I. and Camargo, H. (2012) Soil Moisture Effects on Seasonal Temperature and Precipitation Forecast Scores in Europe. Climate Dynamics, 38, 349-362. https://doi.org/10.1007/s00382-010-0956-2

[12] Wiesner, S., Eschenbach, A. and Ament, F. (2014) Urban Air Temperature Anomalies and Their Relation to Soil Moisture Observed in the City of Hamburg. Meteorologische Zeitschrift, 23, 143-157. https://doi.org/10.1127/0941-2948/2014/0571

[13] Chen, F. and Dudhia, J. (2001) Coupling an Advanced Land Surface-Hydrology Model with the Penn State-NCAR MM5 Modeling System. Part I: Model Implementation and Sensitivity. Monthly Weather Review, 129, 569-585. https://doi.org/10.1175/1520-0493(2001)129<0569:CAALSH>2.0.CO;2

[14] Miralles, D.G., van den Berg, M.J., Teuling, A.J. and de Jeu, R.A.M. (2012) Soil Moisture-Temperature Coupling: A Multiscale Observational Analysis. Geophysical Research Letters, 39, L21707. https://doi.org/10.1029/2012GL053703

[15] Ramarao, M.V.S., Sanjay, J. and Krishnan, R. (2016) Modulation of Summer Monsoon Sub-Seasonal Surface Air Temperature over India by Soil Moisture-Temperature Coupling. MAUSAM, 67, 53-66.

[16] Karl, T.R. (1986) The Relationship of Soil-Moisture Parameterizations to Subsequent Seasonal and Monthly Mean Temperature in the United-States. Monthly Weather Review, 114, 675-686. https://doi.org/10.1175/1520-0493(1986)114<0675:TROSMP>2.0.CO;2

[17] Oglesby, R.J. and Erickson, D.J. (1989) Soil Moisture and the Persistence of North American Drought. Journal of Climate, 2, 1362-1380. https://doi.org/10.1175/1520-0442(1989)002<1362:SMATPO >2.0.CO;2

[18] Zhang, J.Y. and Dong, W.J. (2010) Soil Moisture Influence on Summertime Surface Air Temperature over East Asia. Theoretical and Applied Climatology, 100, 221-226. https://doi.org/10.1007/s00704-009-0236-4

[19] Zhuo, L., Han, D.W. and Dai, Q. (2016) Soil Moisture Deficit Estimation Using Satellite Multi-Angle Brightness Temperature. Journal of Hydrology, 539, 392-405.

[20] Stefanon, M., Schindler, S., Drobinski, P., de Noblet-Ducoudre, N. and D’Andrea, F. (2014) Simulating the Effect of Anthropogenic Vegetation Land Cover on Heatwave Temperatures over Central France. Climate Research, 60, 133-146. https://doi.org/10.3354/cr01230

[21] Lakshmi, V., Piechota, T., Narayan, U. and Tang, C.L. (2004) Soil Moisture as an Indicator of Weather Extremes. Geophysical Research Letters, 31, L11401.

[22] Liang, X., Lettenmaier, D.P., Wood, E.F. and Burges, S.J. (1994) A Simple Hydro- 
logically Based Model of Land-Surface Water and Energy Fluxes for General-Circulation Models. Journal of Geophysical Research-Atmospheres, 99, 14415-14428. https://doi.org/10.1029/94JD00483

[23] Maurer, E.P., O'Donnell, G.M., Lettenmaier, D.P. and Roads, J.O. (2001) Evaluation of the Land Surface Water Budget in NCEP/NCAR and NCEP/DOE Reanalyses Using an Off-Line Hydrologic Model. Journal of Geophysical Research-Atmospheres, 106, 17841-17862. https://doi.org/10.1029/2000JD900828

[24] Abdulla, F.A., Lettenmaier, D.P., Wood, E.F. and Smith, J.A. (1996) Application of a Macroscale Hydrologic Model to Estimate the Water Balance of the Arkansas Red River basin. Journal of Geophysical Research-Atmospheres, 101, 7449-7459. https://doi.org/10.1029/95JD02416

[25] Adam, J.C., Haddeland, I., Su, F. and Lettenmaier, D.P. (2007) Simulation of Reservoir Influences on Annual and Seasonal Streamflow Changes for the Lena, Yenisei, and Ob' Rivers. Journal of Geophysical Research-Atmospheres, 112, D24114. https://doi.org/10.1029/2007JD008525

[26] Mishra, V. and Cherkauer, K.A. (2011) Influence of Cold Season Climate Variability on Lakes and Wetlands in the Great Lakes Region. Journal of Geophysical Research-Atmospheres, 116, D12111. https://doi.org/10.1029/2010JD015063

[27] Tang, C. and Dennis, R.L. (2014) How Reliable Is the Offline Linkage of Weather Research \& Forecasting Model (WRF) and Variable Infiltration Capacity (VIC) model? Global and Planetary Change, 116, 1-9.

https://doi.org/10.1016/j.gloplacha.2014.01.014

[28] Chen, X., Bohn, T.J. and Lettenmaier, D.P. (2015) Model Estimates of Climate Controls on Pan-Arctic Wetland Methane Emissions. Biogeosciences, 12, 6259-6277. https://doi.org/10.5194/bg-12-6259-2015

[29] Torrence, C., and Compo, G.P. (1998) A Practical Guide to Wavelet Analysis. Bulletin of the American Meteorological Society, 79, 61-78. https://doi.org/10.1175/1520-0477(1998)079<0061:APGTWA>2.0.CO;2

[30] Torrence, C., and Webster, P.J. (1999) Interdecadal Changes in the ENSO-Monsoon System. Journal of Climate, 12, 2679-2690. https://doi.org/10.1175/1520-0442(1999)012<2679:ICITEM>2.0.CO;2

[31] Wallace, J.M., Zhang, Y. and Lau, K.H. (1993) Structure and Seasonality of Interannual and Interdecadal Variability of the Geopotential Height and Temperature-Fields in the Northern-Hemisphere Troposphere. Journal of Climate, 6, 2063-2082.

[32] Sheffield, J. and Wood, E.F. (2008) Global Trends and Variability in Soil Moisture and Drought Characteristics, 1950-2000, from Observation-Driven Simulations of the Terrestrial Hydrologic Cycle. Journal of Climate, 21, 432-458. https://doi.org/10.1175/2007JCLI1822.1

[33] Ford, T.W. and Quiring, S.M. (2014) In Situ Soil Moisture Coupled with Extreme Temperatures: A Study Based on the Oklahoma Mesonet. Geophysical Research Letters, 41, 4727-4734. https://doi.org/10.1002/2014GL060949

[34] Ford, T.W., McRoberts, D.B., Quiring, S.M. and Hall, R.E. (2015) On the Utility of In Situ Soil Moisture Observations for Flash Drought Early Warning in Oklahoma, USA. Geophysical Research Letters, 42, 9790-9798.

https://doi.org/10.1002/2015GL066600 
Submit or recommend next manuscript to SCIRP and we will provide best service for you:

Accepting pre-submission inquiries through Email, Facebook, LinkedIn, Twitter, etc. A wide selection of journals (inclusive of 9 subjects, more than 200 journals)

Providing 24-hour high-quality service

User-friendly online submission system

Fair and swift peer-review system

Efficient typesetting and proofreading procedure

Display of the result of downloads and visits, as well as the number of cited articles Maximum dissemination of your research work

Submit your manuscript at: http://papersubmission.scirp.org/

Or contact jwarp@scirp.org 